\title{
Memória e representação: reflexões para a organização do conhecimento
}

\author{
Memororia y representación: reflexiones para la organización del conocimiento
}

Memory and representation: reflections for Knowledge Organization

\section{Mona Cleide Quirino da Silva FARIAS, Maria Leandra BIZELLO}

Departamento de Ciência da Informação, Faculdade de Filosofia e Ciências, Universidade Estadual Paulista - UNESP, Av. Higyno Muzzi Filho, 737, Marília, São Paulo, Brasil, CEP:17525-900; monaquirino@gmail.com; mleandra23@gmail.com

\section{Resumen}

Se discute la concepción de memoria basada en una perspectiva sociocultural en pos de un posible análisis de ésta como elemento de representación del conocimiento en el ámbito de la Organización del Conocimiento. La memoria estudiada desde una perspectiva sociocultural presenta implicaciones para las prácticas y vivencias de los individuos y grupos que comparten experiencias y conllevan significados comunes; y se vuelve de esa forma una representación del conocimiento con características colectivas e híbridas. Nuestro objetivo es retomar algunas concepciones de la memoria para realizar un posterior análisis de la cuestión de la representación del conocimiento. Se presupone que las formas de organizar y representar el conocimiento acarrean implicaciones para los elementos simbólicos cuyo propósito es la representación de la memoria, es decir, una mediación semiótica evidenciada en la medida en que los sujetos comparten un repertorio de signos. Desde este punto de vista, consideramos que la memoria tanto en su dimensión individual como colectiva es un elemento semiótico del conocimiento. Así, la concepción de memoria no se puede reducir apenas a la idea de recuerdo y olvido, ya que el objeto de la memoria se compone de las prácticas individuales y colectivas que se transforman en el camino dinámico en el que los grupos buscan representar su memoria cultural mediada por un contexto histórico y sociocultural dado.

Palabras clave: Memoria. Organización del conocimiento. Mediación semiótica. Memoria cultural.

\section{Introdução}

A memória é aqui compreendida como um elemento de representação do conhecimento. Com base nessa perspectiva entendemos que a memória pode ser também um meio de comunicação, em que grupos buscam compartilhar seus conhecimentos no intuito de manter o significado da memória e de sua representação para posteridade. Nesse sentido, a memória possui um caráter da coletividade, e como memória coletiva esta contribui segundo Pollak (1989), para que seja mantida a coesão de grupos e instituições, e ainda para definir seu lugar.

\begin{abstract}
This paper discusses the concept of memory based on a sociocultural perspective for a possible analysis of it as an element of representation in Knowledge Organization. Memory, from a sociocultural perspective, involves the practices and experiences of individuals and groups that share experiences and carry common meanings and become that, the representation of knowledge with collective and hybrid characteristics. We aim to discuss some conceptions of memory for a further analysis of the issue of knowledge representation. We assume that the ways of organizing and representing knowledge imply symbolic elements whose purpose is the representation of memory, that is, a semiotic mediation evidenced in the way that individuals share a repertoire of signs. Within this scope, we consider memory at both its individual and collective dimensions, as a semiotic element of knowledge. Thus, the conception of memory can not be reduced just to the idea of remembering and forgetting, since the object of memory is the individual and collective practices that turn into the dynamic way in which groups seek to represent their cultural memory mediated by a given historical and sociocultural context.
\end{abstract}

Keywords: Memory. Knowledge organization. Semiotic mediation. Cultural memory.

Destacamos que a memória seja ela definida enquanto social, individual(1), coletiva e cultural, é elemento sígnico de representação que nos permite analisar a dinâmica sociocultural de uma comunidade, pois a partir da memória podemos identificar o comportamento de um grupo e até mesmo conhecer sua identidade. Vale destacar que, a identidade só poderá ser construída no interior de contextos sociais e, por sua vez, determinam a posição dos sujeitos e os orientam nas suas representações e escolhas (Cuche,2002). Vale destacar que, ainda que as identidades sejam construídas no interior dos contextos sociais, elas tomam como referência o que lhe é externo 
a esse espaço social. Nesse sentido, as identidades são formadas por consequência das experiências múltiplas dos sujeitos em interação com demais contextos.

Desse modo, seria interessante compreender sobre códigos culturais, como estruturas complexas que reconhece, armazenam e processam informações com o objetivo de regular e controlar as manifestações da vida, do bio, do socius, do semeion. Constituem um vocabulário mínimo da cultura que se encontra sempre em movimento (Machado, 2003, p. 156), embora muitas vezes não conseguimos interpretá-los em sua plenitude. Nesse sentido, as linguagens necessitam de atenção, pois além de um sistema de comunicação, constituem um sistema modelizante. Enquanto um sistema modelizante e de comunicação, a linguagem/linguagens é(são) responsável(eis) pela transmissão de mensagens representadas na esfera da cultura —Lotman (1978) apud Machado (2007, p. 29)—.

A memória é a manifestação cultural e social do conhecimento construído em uma comunidade que representa um conjunto de saberes e práticas na perspectiva de comunicar ações, atitudes, sentimentos, os quais podem ser rememorados, muitas vezes, por meio de determinados suportes a partir de um contexto escolhido e/ou determinado pelos sujeitos, atores da memória. Vale destacar que quando nos referimos ao termo manifestação, este é compreendido como algo que se apresenta, se revela, se manifesta. Desse modo, entendemos que a memória implica em manifestação de uma vivência, de hábitos, costumes, de fatos, e por isso de uma cultura e sociedade.

Pressupomos que a memória é também motivada por uma variedade de textos, manifestada por múltiplas linguagens que ultrapassam uma representação material, pois a mesma pode ser comunicada por meios visuais, sonoros e arquitetônicos. Os textos são entendidos como um mecanismo semiótico gerador de sentidos (Machado, 2003, p. 169). Para Lotman (1990, p. 8) o texto além de atuar como a matriz de novos significados é também condensador de memória cultural. Para tanto, trazemos também a memória vista na perspectiva da Semiótica da Cultura(2), como algo que é assegurada pela presença de alguns textos e pela unidade de códigos, ou por sua invariância, ou ainda pelo caráter contínuo e regular de sua transformação (Lotman, 1996).

Nesse ínterim, consideramos também que, para comunicar conhecimentos, repassar tradições, hábitos, crenças e desse modo manter o conhecimento do grupo ou comunidade ativo, a memória deveria ser interpretada como um mecanismo representativo de um povo, uma geração, ou seja, que está em processo de transformação e implica assim em diálogos e trocas simbólicas.

Se entendermos a memória como referência de uma cultura, que para Coelho Netto (2012, p. 114), a cultura, em sua conceituação mais ampla, remete à ideia de uma forma que caracteriza o modo de vida de uma comunidade em seu aspecto global, ou seja, totalizante. Assim, seria possível reconhecer que, assim como a cultura possui traços híbridos, também se faz a memória e, dentro de uma perspectiva semiótica, pode motivar nos grupos e comunidades processos de semiose, pois é um processo de veiculação dos signos e/ou a própria evolução dos signos. Isso quer dizer que a semiose seria a constante no percurso continuum percorrida pelo signo, isto é de evolução de significados.

Parafraseando Braga (2000), a memória humana é concebida como um processo elaborado no movimento coletivo que emerge nas interações, e está constituído na cultura. Esse processo pode ser entendido do ponto de vista dos signos(3) dados em uma dimensão simbólica (orais e escritos), como também nos signos icônicos (imagens), os quais podem servir de suporte para a construção da memória. Nesse sentido, a memória pode ancorar-se em diversos suportes e/ou linguagens como, por exemplo, em um texto, na comunicação oral, por meio de sons, de imagens, entre outros (Gondar, 2005).

Para tanto, entende-se que a memória não é algo estagnado finalizado, pelo contrário, a memória é dinâmica e essa característica deve ser reconhecida principalmente quando buscamos representar algo, pois representar não condiz em ditar o que uma coisa é ou foi, mas permitir reconhecer tal coisa em sua dinâmica, mas não desconsiderar as peculiaridades signicas da memória.

Nesse sentido, é necessário ter a consciência de possíveis transformações desde um ponto de vista das linguagens adotadas e assimiladas por culturas e sociedades distintas, como do sentido adquirido ao longo de seu percurso representativo e de agregação de sentidos. Daí surge a questão: será que a memória materializada, isto é, enquadrada(4) em um dado suporte informacional, institucionalizada condiz de fato com a vivência, a história de um povo, ou apenas representa um recorte de um acontecimento e lou invenção?

Tal questão norteia esse artigo e nos possibilita refletir sobre formas de representação da memória e ainda de como a memória de um determinado grupo pode ser representada tendo em vista que a mesma pode sofrer influências externas e por isso requer instrumentos apropriados 
que consigam garantir (Beghtol, 2002) uma representação que mais se aproxime da realidade e que acima de tudo reconheça a hibridez de significados que perpassam uma determinada memória.

Vale ressaltar que já existem estudos(5) que discorrem sobre o conceito de memória na Ciência da Informação, mas este artigo não possui esse intuito. Nossa intenção é refletir sobre a concepção de memória e apresentá-la sob a perspectiva de mecanismo gerador de conhecimentos, isto é, como elemento de organização que pode desencadear em discussões posteriores sobre como a memória de uma comunidade específica pode ser representada em um sistema de organização do conhecimento desde que leve em consideração os processos dialógicos e semióticos da representação e principalmente as peculiaridades simbólicas da cultura e da comunidade que gera tal memória.

\section{A memória como objeto do conhecimento}

Objetiva-se discutir brevemente sobre a memória como um objeto do conhecimento na perspectiva de reconhecer que as comunidades ou grupos com base em suas culturas, costumes e hábitos desenvolvem memória e esta pode ser objeto de conhecimento na medida em que alcança uma representação, seja por meio de um suporte físico/material, imaterial ou por outros meios de expressão e representação da memória em uma dada cultura, como por exemplo, a dança - em suas várias singularidades artísticas, a prática da oralidade em algumas sociedades etc.

Vale dizer que a memória é construída numa dimensão coletiva mas que desfruta de individualidades, e por isso está sujeita a transformações. Assim também entendemos o conhecimento, algo em plena construção. Ademais, a memória nos remete sempre ao passado, mas um passado comentado, ou representado em um dado presente circunstanciado. Automaticamente $\mathrm{o}$ passado rememorado nos fornece lembranças e estas são parte de um conhecimento compartilhado a partir de uma memória. O passado rememorado a partir de lembranças coletivas ou individuais, são parte de um conhecimento compartilhado, uma memoria ou memorias.

Contudo, Halbwachs (2004, p. 26-34) destaca que:

[...] nossas lembranças permanecem coletivas, e elas nos são lembradas pelos outros, mesmo que se trate de acontecimentos nos quais só nós estivemos envolvidos, e com objetos que só nós vimos. É porque, em realidade, nunca estamos sós. Não é necessário que outros homens estejam lá, que se distingam materialmente de nós: porque temos sempre conosco e em nós uma quantidade de pessoas que não se confundem[...]. Para que nossa memória se auxilie com a dos outros, não basta que eles nos tragam seus depoimentos: é necessário ainda que ela não tenha cessado de concordar com suas memórias e que haja bastante pontos de contato entre uma e outras para que a lembrança que nos recordam possa ser reconstruída sobre um fundamento comum.

A capacidade de lembrar na concepção de Halbwachs, só é possível se assumimos o ponto de vista de um ou mais grupos e nos situamos em uma ou mais correntes do pensamento coletivo (Halbwachs, 2004, p. 31):

Assim, se encontrarmos mais tarde membros de uma sociedade que se tornou para nós a tal ponto estranha, por mais que nos encontremos no meio deles, não conseguimos reconstituir com eles o grupo antigo. É como se abordássemos um caminho que percorremos outrora, mas de viés, como se o encarássemos de um ponto de onde nunca o vimos.

Para explorar nossa capacidade de lembrar, a linguagem é fundamental, pois pode ampliar nosso repertório de lembranças e auxiliar na representação da memória. Assim entendemos que a linguagem para a memória é um elemento indissociável da representação. Santos (2003, p. 46) considera que "[...] a linguagem é uma forma de memória que nos antecede. Ela está lá, seja na nossa mente em forma de pensamento, seja organizada sob a forma de discursos ou textos produzidos numa determinada cultura."

Dessa maneira, visualiza-se de um modo geral que memória possui a potencialidade de ser um objeto do conhecimento. Porém é preciso entender que todo e qualquer conhecimento é desenhado e articulado com base em um domínio, o qual irá determinar as formas de análise e projeção de tal conhecimento. Nesse contexto, entendemos os domínios como campos de atividades que compartilham de conhecimentos que se aproximam, tendo em vista interesses comuns como, por exemplo, a Semiótica da Cultura e os campos de investigações da Antropologia, Linguística estrutural, entre outras.

No entanto, o conhecimento implica em operações organizadas e dialógicas em constante processamento, se trata de algo construído não somente pelo indivíduo, mas pelas relações com o coletivo. Sendo assim, entendemos que o caráter dialógico do conhecimento requer a compreensão do contexto no qual foi criado, isto é, necessita conhecer a memória pela qual tal conhecimento foi elaborado.

Com base nisso, compartilhamos da perspectiva do "conhecimento em ação" como destacado por 
Dahlberg (1993), e acrescentamos também que "a cultura, assim como a linguagem e possivelmente a memória são elementos em ação" e por conseguinte estão imbuídos na configuração do/de conhecimento(s).

Desse modo, entendemos que o conhecimento pode ser descrito como a soma de experiências, organizadas e sistematizadas, e por isso não é algo acabado. Assim, devemos considerar que em cada contexto, por ocasião das relações estabelecidas entre os sujeitos, numa dada cultura o conhecimento possui características distintas e está se renovando. A memória nesse contexto é elemento determinante para o conhecimento.

No âmbito do campo da Organização do Conhecimento resgatamos de maneira breve algumas concepções sobre conhecimento que nos auxiliam em entender este como potencializado por uma memória cultural. Barité (2001, p. 42, tradução nossa) destaca que o conhecimento implica em um produto social e uma necessidade social, o autor ressalta ainda que

[...], em suma, pode ser visto como o saber acumulado da humanidade, mas também fornecedor permanente que atenda às necessidades sociais e identifica "lacunas" onde novos conhecimentos são necessários para se regenerar.

Fernandez-Molina (1994, p. 328), destaca que o termo conhecimento constitui-se na conversão de informação, em que esta última só pode tornar-se conhecimento na medida em que venha a provocar modificação na estrutura do conhecimento de um determinado receptor. Podemos dizer que o conhecimento implica no processo de alteração sobre um dado conhecimento anteriormente apresentado por um sujeito em um determinado contexto.

O conhecimento é uma construção coletiva e, portanto, reflexo de uma determinada cultura resguardada e revelada em uma memória. Os conhecimentos de uma cultura encontram-se em constante relação de busca por sentido. Ainda, enquanto produto cultural, os conhecimentos são resultantes de inúmeras condições socioculturais que interagem em tempo e espaço da cultura em sua dimensão híbrida e dialógica. Entende-se que "[...] é na interação [...] onde residem o sentido, a cultura, o conhecimento e a memória" (García Gutiérrez, 2008, p. 42).

Destaca-se que a memória consiste também na tecitura de uma cultura a qual explicita aspectos individuais e sociais. Pois, "mesmo no nível individual, o trabalho da memória é indissociável da organização social da vida" (Pollak, 1989, p. 11). Nora (1993, p. 9) considera a memória como um processo vivido, conduzido por grupos vivos, portanto, em evolução permanente e suscetível a todas as manipulações. Ainda ressalta que:

A memória é vida, sempre carregada por grupos vivos e, nesse sentido, ela está em permanente evolução, aberta à dialética da lembrança e do esquecimento, inconsciente de suas deformações sucessivas, vulnerável a todos os usos e manipulações, susceptível de longas latências e de repentinas revitalizações.

A memória está atrelada a uma cultura. E a cultura, enquanto universo simbólico e representativo do conhecimento, possui a capacidade de criar e desenvolver linguagens o que favorece a dinâmica da mesma e suas possíveis relações interculturais. Diante desse universo simbólico mergulhada em diversos signos é que a memória passa a ser projetada e posteriormente representada nos ditos "lugares de memória".

Para Nora (1993, p. 21) esses lugares são identificados por meio de uma acepção triádica, isto é, como "lugares materiais, lugares funcionais e lugares simbólicos". O autor entende que tais lugares são carregados de necessidade de memória. Contudo, ressaltamos que é importante a reflexão sobre os lugares de memória e a representação como criações necessárias para a existência e/ou consciência de uma memória.

Nessa perspectiva, de lugares de memória, entendemos que estes representam mais que meros monumentos, espaços institucionalizados, são também documentos e portanto requerem atividades interpretativas que possibilitem entender a procedência da memória veiculada. Para tanto, é necessário realizar leituras sobre sua representação assim como das intenções de quem representou tal memória.

Numa breve sistematização, Pollak (1992, p. 200-212) observa que a memória, seja ela individual ou coletiva, tem como elementos constitutivos acontecimentos, pessoas e lugares. Na perspectiva de acontecimentos tem-se que as experiências são as vividas pessoalmente e ainda aquelas que, não vivenciadas particularmente por nós, foram pelo grupo a que se pertence. Aqui entraria a noção de uma memória "herdada".

Sendo composta por pessoas, a memória agrega personagens, seja do nosso tempo ou não, sobre as quais se sabem coisas como se as conhecêssemos. Numa compreensão dos lugares podemos ter como exemplo - uma escola espaço de uma infância, da qual guardamos registros afetivos, assim como monumentos, documentos, o espaço da casa - ambiente familiar onde compartilhamos saberes e afetividades etc. 
De todo modo, Halbwachs (2004, p. 12) comenta que para que nossa memória se beneficie da dos outros, não basta apenas seus testemunhos, é preciso também que haja um acordo com suas memórias e que seja suficiente os pontos de contato entre ela e as outras memórias, para que a lembrança que os outros nos fornecem possam ser reconstruídas sobre uma base comum.

Em linhas gerais, a memória como uma manifestação de um grupo que deseja destacar um conhecimento dentro de uma relação entre passado e presente pode ser compreendida como um dispositivo do conhecimento, pois por meio da memória, no uso de linguagens e dentro de uma dinâmica cultural, é possível desmembrar conteúdos, informações e (re)construir conhecimentos, assim como representá-los.

\section{A memória e suas múltiplas representações}

Nos encontramos imersos em contextos dinâmicos de representação, enxertados por diversos mecanismos, linguagens e suportes que buscam representar um conhecimento, ou mesmo uma memória. Nesse sentido, como compreender a memória dentro desses contextos híbridos de representação?

Um exemplo que podemos mencionar é o ciberespaço, como uma nova forma/função de produção, representação, organização do conhecimento e memória (Monteiro, 2002; 2006). Nessa perspectiva a memória virtual representada no ciberespaço possui, de algum modo, algumas aproximações com a memória da sociedade oral, como por exemplo, no uso do discurso narrativo, no uso das imagens, e as possibilidades de esquecimento.

No entanto, este cenário do ciberespaço está se configurando como um novo tipo de memória que se distancia da característica mnemotécnica, como também não se limita na memória representada a partir da materialidade dos livros, pelo contrário, este novo cenário evidencia a dinâmica do signo em favor do conhecimento em um fluxo continuo pelo qual a memória também está sujeita.

Aqui tentamos considerar que a memória pode estabelecer diálogos por meio de múltiplas representações em vários ambientes e linguagens, pois a representação se situa entre o vivido e o concebido, atuando como mediadora de um conhecimento que se encontra direta ou indiretamente atrelado a uma determinada memória.

Desse modo, é possível questionar se representar a memória dentro de uma dimensão coletiva e/ou individual requer apenas o uso de uma única linguagem e ainda se tal linguagem representa de modo coerente a memória de um grupo/comunidade.

Afirmamos que a representação se origina em um sujeito individual ou coletivo imerso em condições específicas de seu espaço e tempo, e refere-se a um objeto. Ainda ao se referir sobre representações tem-se que tais representações atuam como "[...] uma forma de conhecimento socialmente elaborado e compartilhado, com um objetivo prático, e que contribui para a construção de uma realidade comum a um conjunto social" (Jodelet, 2002, p .22).

No âmbito da Organização do Conhecimento Brascher e Café $(2008$, p. 6) destacam sobre o ponto de vista da representação do conhecimento que trata de temáticas que nos encaminham ao "mundo dos conceitos" e não meramente ao dos registros de informação. Ao partir dessa compreensão a representação do conhecimento busca refletir uma visão consensual sobre a realidade a ser representada.

Em outras palavras, a representação é um processo reflexivo sobre os contextos em que estão inseridos diversos domínios de conhecimento. Podemos dizer que, as representações em um dado domínio necessita também o reconhecimento da memória mediada nos mesmos e que devem ser levado em conta os aspectos sociais, culturais e também éticos da representação.

Guimarães e Milani (2011, p. 1) consideram a representação do conhecimento como sendo uma tomada de decisão e atenta para que seus produtos devam figurar-se defensáveis. Ainda no contexto da discussão os autores reforçam sobre os problemas éticos das bias no universo da representação do conhecimento. Segundo Milani et al (2009) o termo bias possui o sentido de desvios em inglês, e sesgos em espanhol. Tal termo está presente em discussões e trabalhos de caráter teórico, em sua maioria, que envolvem a representação do conhecimento.

No escopo dessa discussão é necessário ressaltar que "[...] as representações são apenas uma parte: aquela que se cristalizou e se legitimou em uma coletividade". Ainda nesse raciocínio, a memória como um processo, "[...] é bem mais que um conjunto de representações; ela se exerce também em uma esfera irrepresentável: modos de sentir, modos de querer, pequenos gestos, práticas de si, ações políticas inovadoras" (Gondar e Dodebei, 2005, p. 24).

Contudo, em se tratando não apenas do conhecimento mais também da memória esta não pode ser reduzida à representação. Pois não "Pode- 
mos articular o afeto e a representação na produção da memória como partes integrantes de um mesmo processo." (Gondar e Dodebei, 2005, p. 25). No entanto, uma representação social, por exemplo, "[...] é algo mais que uma idéia genérica e instituída que se impõe a nós: todas as representações são inventadas e somos nós que as inventamos, valendo-nos de uma novidade que nos afeta e de nossa aposta em caminhos possíveis" (Gondar e Dodebei, 2005, p. 25).

Vale destacar que (Oliveira e Rodrigues, 2011, p. 313):

A sociedade do efêmero, na qual se defrontam questões de ordem ideológica, ética, econômica e tecnológica, parece reforçar a necessidade de tornar explícitas as concepções de memória que permeiam o conhecimento produzido pela Ciência da Informação. Isto talvez ajude a entender o papel que a área pretende, ou deveria pretender desempenhar no processo social de construção da memoria.

No mais, a memória é uma construção social, produzida pelos homens a partir de suas relações, de seus valores e de suas experiências vividas. Ela sofre transformações à medida que 0 tempo passa, a história dos indivíduos toma um novo rumo. Assim, pode-se dizer que a memória não se restringe apenas um registro dos fatos, mas uma combinação de construções sociais do passado, que se agregam a fatores significantes da vida social de um presente, sendo permanentemente reconstruída.

Nesse sentido (Halbwachs, 2004, p. 35):

Não é suficiente reconstituir peça por peça a imagem de um acontecimento do passado para se obter uma lembrança; é necessário que esta reconstrução se opere a partir de dados ou de noções comuns que se encontram tanto no nosso espírito como no dos outros, porque elas passam incessantemente desses para aquele e reciprocamente, o que só é possível se fizeram e continuam a fazer parte de uma mesma sociedade.

Pollak (1989) enfatiza que a referência ao passado serve para manter a coesão dos grupos e das instituições que compõem uma sociedade, para definir seu lugar respectivo, sua complementaridade, mas também as posições irredutíveis.

A recordação passa a ser afetada por transformações inconscientes, em função de interesses e sentimentos, individuais ou coletivos, todavia, "[...] esse movimento só é possível se as pessoas fizeram ou ainda fazem parte de um mesmo grupo social" (Braga, 2000, p. 51).

Nessa perspectiva, a memória coletiva só se efetiva na medida em que os sentimentos, pensamentos e ações de cada indivíduo são expressos nos meios e circunstâncias sociais, onde este possui vínculo, convivência e conhecimento, isto é, onde compartilhe de uma cultura ou ainda de um repertório de signos que marcam a sua identidade a partir de linguagens mediadas.

Consideramos que as linguagens são, dessa maneira, as formas dinâmicas de expressão da cultura, e também da memória, visto que abarcam a diversidade cultural existente nos grupos e comunidades. Nesse sentido, as culturas não devem ser entendidas como estáticas, pois "Entre as culturas se produz uma interação simbólica" (García Gutiérrez, 2004, p. 113, tradução nossa).

Em suma, na ocasião da representação da memória, retomamos brevemente a concepção de exomemória de García Gutiérrez (2002) onde esta constitui nas diversas formas de registrar o conhecimento, como por exemplo, os livros, as fotografias, as gravuras, os quadros, as esculturas, etc. Sobre tal discussão, vale destacar a concepção do autor sobre conhecimento e memória, em que o mesmo trata tanto o conhecimento quanto a memória como sinônimos.

\section{Considerações}

Entende-se que a discussão da memória é um tema aberto e por isso nos possibilita ampliar nossas concepções. Dessa maneira, reconhecemos que as formas de organizar e representar o conhecimento implicam em elementos simbólicos cujo propósito seja a representação da memória, a qual implica em mediação semiótica evidenciada na medida em que os sujeitos compartilham de um repertório de signos.

Neste escopo, consideramos que a memória tanto em sua dimensão individual e/ou coletiva, pode ser configurada como elemento semiótico do conhecimento e, por conseguinte, da representação. Em alguns aspectos a memória pode vir a ser compreendida como o próprio conhecimento no sentido de compartilhar saberes mediante as práticas culturais de um grupo ou comunidade.

Memória, no ponto de vista dessa discussão, se configura como um dispositivo semiótico articulado e transformado pelos indivíduos nas relações com o coletivo e que não está alheia à um passado que em dimensões múltiplas dialoga com um presente para uma suposta representação. A representação nesse contexto seria a forma de comunicação de uma memória transposta em um determinado suporte materializado ou não, mas que garanta seu significado.

Portanto, a concepção de memória não pode se reduzir apenas a ideia de lembrança e esquecimento, nem mesmo ser reconhecida a partir de 
um único modo de representação, pois o objeto da memória constitui das práticas individuais e coletivas que transformam-se no percusso dinâmico em que os grupos buscam representar sua memória cultural condicionada a um dado contexto histórico e sociocultural.

\section{Notas}

(1) Para Halbwachs (1990), a memória individual não está inteiramente fechada. Ela é limitada no tempo e no espaço. A memória coletiva também sofre os mesmos limites. Os acontecimentos históricos são auxiliares na nossa memória; não desempenham outro papel, senão as divisões do tempo assinaladas em relógio ou determinadas pelo calendário.

(2) Também conhecida por Semiótica Russa. Suas primeiras perspectivas de estudos tiveram como palco a Escola de Tártu-Moscou, na Estônia, que em meados da década de 1960 desenvolveu as primeiras discussões sobre sistemas de signos: texto cultural, códigos culturais, linguagens etc. Seu campo possui caráter transdiciplinar e dialoga com diversas disciplinas como a Teoria literária, Linguística estrutural, Semiótica, Crítica da arte, Cibernética, Teoria da Informação e da Comunicação, Antropologia, Etnologia etc.

(3) Peirce $(1990$, p. 4), diz que o signo é qualquer coisa que conduz alguma outra coisa (seu interpretante). Para Coelho Netto (2010, p. 56), a concepção de signo dada por Peirce é aquilo que sob determinado aspecto representa algo para alguém. Na concepção atribuída por Saussure (1970, p. 81) o signo linguístico constitui de uma unidade psíquica de duas faces que seria a união entre a imagem acústica e o conceito, ou significado e significante.

(4) O termo exposto, ressalta a noção de "enquadramento de memória" que segundo Michel Pollak (1989), além de servir como um referencial do passado evidencia a disputa em torno da memória e revela um modo de manter a coesão entre os grupos sociais.

(5) Ver a tese de Oliveira (2010) cujo título é: "O conceito de memória na ciência da informação no brasil: uma análise da produção científica dos programas de pós-graduação".

\section{Referências}

Barité, Mário (2001). Organización del conocimiento: un nuevo marco teórico-conceptual em Bibliotecología y Documentación. // Carrara, Kester. (ed.). Educação, universidade e pesquisa. Marília: Unesp-Marília-Publicações. 2001. 35-60.

Beghtol, Clare (2002). Universal concepts, cultural warrant, and cultural hospitality. // López-huertas, M. J. (ed.). Challenges in knowledge representation and organization for the 21 centurry: integration of knowledgeacrouss boundaries. Wurzburg: Ergon-Verlag, 2002. 45-49. (Advances in Knowledge Organization, 8).

Braga, Elizabeth dos Santos (2000). A Construção Social da Memória: uma perspectiva histórico- cultural. ljuí: Unijuí, 2000.

Brascher; Marisa; Café, Lígia (2008). Organização da informação ou organização do conhecimento? // Encontro Nacional de Pesquisa em Ciência da Informação - Enancib, 9. São Paulo: ECA/USP, 2008. http://www.ancib.org.br/media/dissertacao/1835.pdf (2013-05-18).

Coelho Netto, José Teixeira (2010). Semiótica, Informação e Comunicação. São Paulo: Perspectiva, 2010.
Coelho Netto, José Teixeira (2012). Dicionário crítico de política cultural: cultura e imaginário. 2.ed. rev.ampl. São Paulo: lluminuras, 2012.

Cuche, Denys (2002). A noção de cultura nas ciências sociais.2. ed. Bauru: EDUSC, 2002.

Dahlberg, Ingetraut (1993). Knowledge organization: its scopes and possibilities. // Knowledge Organizaton. Frankfurt. 20:4, 211-222.

Fernandez-molina, Juan Carlos (1994). Enfoques objetivo y subjetivo del concepto de información. // Revista Española de Documentación Científica. 17:3. 320-331.

García Gutiérrez, Antonio (2002). Exomemoria y cultura de frontera: hacia una ética transcultural de la mediación. // VII Congreso Internacional sobre Organización del Conocimiento celebrado en Granada (España).

García Gutiérrez, Antonio (2004). Otra memoria es posible: estrategias descolonizadoras del archivo mundial. SeviIla: Universidad de Sevilla. 2004.

García Gutiérrez, Antonio (2008). Outra memória é possível: estratégias descolonizadoras do arquivo mundial. Petrópolis: Vozes. 2008.

Gondar, Jô; Dodebei, Vera Lucia Doyle (eds.). ( 2005) O que é Memória Social? Rio de Janeiro: Universidade Federal do Rio de Janeiro. 2005

Guimarães, José Augusto Chaves; Milani, Suellen Oliveira (2011). Problemas éticos em representação do conhecimento: uma abordagem teórica. // DataGramaZero. 12:1, 1-18.

Halbwachs, Maurice (1990). A memória coletiva. tradução de Laurent Leon Schaffer. São Paulo:Vértice, 1990.

Halbwachs, Maurice (2004). A memória coletiva. São Paulo: Centauro, 2004.

Jodelet, Denise (2002). Representações Sociais: um domínio em expansão. // Jodelet, Denise. (ed.). As Representações Sociais. Rio de Janeiro: Eduerj, 2002.

Lopes, Luís Carlos (1998). A imagem e a sombra da arquivística. Rio de Janeiro: Arquivo Público, 1998.

Lotman, luri. M. (1990). Universe of the mind: a semiotic theory of culture. London: Tauris, 1990

Lotman, luri. M. (1996). La semiosfera I: semiótica de la cultura y del texto. Tradução de Desiderio Navarro. Valência: Frónesis Cátedra, 1996.

Machado, Irene (2003). Escola de Semiótica: a experiência de Tártu - Moscou para o estudo da cultura. São Paulo: Ateliê Editorial. 2003.

Machado, Irene (2007) Semiótica da Cultura e Semiosfera. São Paulo: Annablume/Fapesp, 2007.

Millani, Suellen Oliveira; Guimarães, José Augusto Chaves; Pinho, Fábio de Assis; Fernández-Molina (2009). Os desvios na representação do conhecimento em um contexto multicultural: abordagens teóricas. // Romero, N. L. (ed.). Nuevas perspectivas para la difusión y organización del conocimiento. Valencia: Universidad Politécnica de Valencia. 2009. 204-218.

Monteiro, Silvana Drumond (2003). A organização virtual do conhecimento no ciberespaço:os agenciamentos do sentido e do significado. Pontifícia Universidade Católica de São Paulo, São Paulo. 2003. Tese de doutorado.

Monteiro, Silvana Drumond (2006). O ciberespaço e os mecanismos debusca: novas máquinas semióticas. // Ciência da Informação. Brasília. 53:1, 31-38, (jan./abr.) http://www.ibict.br/cienciadainformacao/viewarticle.php?id=738\&layout=abstract (2006-03-20).

Nora, Pierre (1993). Entre memória e história: a problemática dos lugares. // Projeto História. São Paulo. 10, 7-28.

Oliveira, Eliane Braga de; Rodrigues, Georgete Medleg (2011). O conceito de memória na Ciência da Informação: 
análise das teses e dissertações dos programas de pósgraduação no Brasil. // Liinc em Revista. 7:1. Rio de Janeiro. 311-328 http://www.ibict.br/liinc

Oliveira, Eliane Braga de (2010). O conceito de memória na ciência da informação no Brasil: uma análise da produção científica dos programas de pós-graduação. Universidade de Brasília, Brasília, 2010. Tese de doutorado.

Peirce, Charles. Sanders (1990). Semiótica. 2. ed. São Paulo: Perspectiva. 1990.

Pollak, Michael (1992). Memória e identidade social. // Estudos Históricos. Rio de Janeiro. 5:10. 1-15.
Pollak, Michael (1989). Memória, Esquecimento, Silêncio. // Estudos Históricos, tradução de Dora Rocha Flaksman. Rio de Janeiro. 2:3, 3-15.

Santos, Myrian Sepúlveda dos (2003). História e memória: o caso do ferrugem. // Revista Brasileira de História. São Paulo. 23:46, 271-295.

Saussure, Ferdinand. de. (1970). Curso de lingüística geral. 2. ed. São Paulo: Cultrix. 1970.

Enviado: 2016-05-14. Segunda versión: 2016-06-29. Aceptado: 2016-09-15. 